\title{
Review
}

\section{Persimmon breeding in Japan for pollination-constant non-astringent (PCNA) type with marker-assisted selection}

\author{
Akihiko Sato*1) and Masahiko Yamada $^{2)}$ \\ 1) Grape and Persimmon Research Division, NARO Institute of Fruit Tree Science, 301-2 Akitsu, Higashihiroshima, Hiroshima 729- \\ 2494, Japan \\ 2) NARO Institute of Fruit Tree Science, 2-1 Fujimoto, Tsukuba, Ibaraki 305-8605, Japan
}

\begin{abstract}
Oriental persimmon (Diospyros kaki) originated in Eastern Asia, and many indigenous cultivars have been developed in China, Japan, and Korea. These cultivars are classified into four groups based on their natural astringency loss on the tree and seed formation: pollination-constant non-astringent (PCNA), pollinationvariant non-astringent (PVNA), pollination-constant astringent (PCA), and pollination-variant astringent (PVA). PCNA is the most desirable type because the fruit can be eaten without any postharvest treatment; therefore, one of the goals of our persimmon breeding programs is to release superior PCNA cultivars. The PCNA genotype is recessive to the other three non-PCNA genotypes, and PCNA-type $\mathrm{F}_{1}$ offspring are obtained exclusively from crosses among PCNA genotypes. Moreover, the number of superior PCNA crossparents have been limited. In the late 1980s, inbreeding depression became obvious, especially in terms of fruit size, tree vigor, and productivity. To mitigate the inbreeding, a backcross program using PCNA [(nonPCNA $\times$ PCNA) $\times$ PCNA] was started in 1990 . This process, however, was inefficient because only $15 \%$ of the offspring were PCNA, and all offspring had to be grown to the fruiting stage. Therefore, molecular markers linked to the PCNA locus were developed for discriminating PCNA offspring. A molecular marker linked to Chinese PCNA has also been developed.
\end{abstract}

Key Words: astringency, Diospyros kaki, fruit, inbreeding depression, MAS.

\section{Introduction}

Oriental persimmon or persimmon (Diospyros kaki Thunb.) originated in Eastern Asia, and many indigenous cultivars have been developed in China, Japan, and Korea (Agricultural Research Station 1912, Cho and Cho 1965, Wang et al. 1997). Currently, persimmon is produced worldwide, including in Brazil, Israel, Italy, Spain, Azerbaijan, Uzbekistan, New Zealand, and Australia (Food and Agriculture Organization of the United Nations 2015). In spite of the large worldwide production of this fruit, new persimmon cultivars developed by cross-breeding have been released only in Japan and Korea. New cultivars have been released in Japan since 1959 and in Korea since 2012. Persimmon has been a major fruit crop in Japan for many years, where it ranks fourth in fruit production, after citrus, apple, and Japanese pear (Ministry of Agriculture, Forestry and Fisheries 2015).

Communicated by H. Iketani

Received August 7, 2015. Accepted November 18, 2015.

*Corresponding author (e-mail: satoaki@affrc.go.jp)
The breeding and genetics of persimmon in Japan has been reviewed by Yamada (1993, 2005, 2013); breeding and genetics of persimmon around the world have been reviewed by Yonemori et al. (2000) and Yamada et al. (2012a). This review focuses on the recent development of practical DNA marker-assisted breeding for astringency type, which enables genotypes bearing non-astringent fruit to be rapidly distinguished from those bearing astringent fruit, and on the breeding targets in our program to develop superior non-astringent cultivars.

\section{Classification of oriental persimmon based on} astringency

Oriental persimmon fruit accumulates water-soluble tannins in the tannin cells in the flesh during fruit development, and these tannins are responsible for the astringent taste (Yonemori et al. 2000). Some Oriental persimmon cultivars lose fruit astringency at maturation (non-astringent cultivars), but others do not (astringent cultivars), so cultivars can be classified on that basis. Hume (1914) classified these cultivars into two groups based on differences in flesh coloration 
as influenced by pollination (seed formation). In one group, the fruit flesh does not change color by seed formation (pollination-constant, PC); in the other, the flesh darkens by seed formation (pollination-variant, PV). In PV cultivars, the dark flesh color is caused by oxidized and insoluble tannin substances. Combining these two classification methods, persimmon cultivars have been commonly classified into four types: pollination-constant non-astringent (PCNA), pollination-variant non-astringent (PVNA), pollinationconstant astringent (PCA), and pollination-variant astringent (PVA) (Kajiura 1946, Kitagawa and Glucina 1984, Yonemori et al. 2000).

In Japan, the fruit of astringent cultivars was consumed as over-ripened soft fruit because the level of astringency decreased in the process of fruit softening. In addition, the fruit has been consumed as dried fruit, which is prepared by peeling prior to drying. In the non-PCNA cultivars, including PVNA cultivars, the soluble tannins that cause astringency become insoluble in the presence of acetaldehyde, making the fruit less astringent (Kitagawa 1970). At the present day, astringency is generally removed from astringent cultivars by artificial treatments, such as exposure to carbon dioxide gas or ethanol vapor (Yamada 2006, Yamada et al. 2002b), which causes an accumulation of acetaldehyde in the fruits. In PV cultivars, the seeds themselves produce acetaldehyde and ethanol, causing the soluble tannins to condense or coagulate in the fruit flesh (Sugiura and Tomana 1983); these insoluble tannins then become oxidized and darkened. Ikeda et al. (1985) showed that the PVNA, PVA, and PCA traits are threshold characters separated by the level of ethanol and acetaldehyde production in their seeds, and that their inheritance is quantitative.

There are many local varieties of both PV types (PVNA and PVA) in Japan (Agricultural Research Station 1912, Yamada et al. 1994a). In contrast, PV types are rarely found in Korea (Cho and Cho 1965, Kikuchi 1948) and not at all in China (Wang 1982), indicating that the PV trait is of Japanese origin. Although there are many astringent and PVNA cultivars in Japan, there are very few local PCNA cultivars. The national institute in Japan conserves around 600 cultivars/selections in Akitsu, Hiroshima. However, only 18 PCNA cultivars of Japanese origin, excluding bud sports, synonyms, and newly released cultivars, are conserved in Akitsu (Yamada 2005). In PCNA cultivars of Japanese origin, the tannin cells in the fruit flesh cease to develop in late June, whereas those of non-PCNA cultivars continue to increase in size until the end of July (Yonemori and Matsushima 1985). Consequently, the final size of the tannin cells is much smaller in the PCNA fruits than in nonPCNA fruits.

The PCNA trait is recessive to the non-PCNA trait and is qualitatively inherited (Ikeda et al. 1985). Crosses among PCNA cultivars/selections of Japanese origin yielded only PCNA $F_{1}$ offspring because the parents are homozygous for the recessive allele, whereas almost no $\mathrm{F}_{1}$ PCNA offspring resulted from crosses between PCNA and non-PCNAs
(Ikeda et al. 1985, Yamada and Sato 2002). Only about 15\% of PCNA offspring were obtained from backcrosses [(non-PCNA $\times$ PCNA) $\times$ PCNA] (Ikeda et al. 1985). The PCNA/non-PCNA genotype is controlled by a single locus (designated AST/ast or $\mathrm{A} / \mathrm{a}$ ), but the hexaploid nature of persimmon complicates the segregation ratios. The presence of one dominant $A S T$ allele is sufficient to express the non-PCNA phenotype, whereas the PCNA phenotype is expressed only when all alleles are recessive for ast (denoted as aaaaaa) (Akagi et al. 2010).

The existence of a non-astringent persimmon cultivar of Chinese origin, 'Luotian-Tianshi', was first reported by Wang (1982); it had been previously believed that no non-astringent cultivars of Chinese origin existed. Its distribution was within a narrow area extending from Hubei Province to Henan Province. Subsequently, several other non-astringent cultivars, including 'Tianbaogai' (former name, 'Baogai Tian Shi'), were found (Yonemori et al. 2005). 'Luotian-Tianshi' was introduced to Japan by the national institute in 1988, and it was subsequently identified as a PCNA-type cultivar by Yamada et al. (1993a). Yamada et al. (1993a) also reported that 'Luotian-Tianshi' fruit had some astringency at maturity, which may be an obstacle to its use in PCNA breeding. Using amplified fragment length polymorphism (AFLP) markers, Kanzaki et al. (2000b) showed a close relationship among the PCNA cultivars of Japanese origin, but a distant relationship was observed between 'Luotian-Tianshi' and the PCNA cultivars of Japanese origin. Random amplified polymorphic DNA (RAPD) analysis also showed that the PCNA cultivars of Chinese origin were distant from those of Japanese origin (Luo et al. 1999).

The genetic behavior of the Chinese PCNA trait of 'Luotian-Tianshi' differs from that of Japanese PCNA (Ikegami et al. 2004, 2006). All offspring from crosses among Japanese PCNA cultivars contained only small tannin cells, resulting in PCNA phenotypes, and those from several crosses between PVNA and Japanese PCNA cultivars had only large tannin cells and were non-PCNA phenotypes. On the other hand, hybrids between 'Luotian-Tianshi' and Japanese PCNA cultivars segregated into two offspring groups that had either small or large tannin cells (Ikegami et al. 2004). Moreover, about $50 \%$ of the offspring from crosses between 'Luotian-Tianshi' and non-PCNA cultivars had the PCNA phenotype, indicating that the PCNA trait of 'Luotian-Tianshi' is genetically dominant to the non-PCNA traits and that 'Luotian-Tianshi' is likely heterozygous (Ikegami et al. 2006). In addition, Ikegami et al. (2005) revealed that the tannin molecules from 'Luotian-Tianshi' are larger than those of PCNA cultivars of Japanese origin. Moreover, 'Luotian-Tianshi' does not have any ast alleles (Akagi et al. 2010). Conversely, Japanese PCNA local cultivars do not have any dominant Chinese PCNA alleles because crosses between Japanese PCNA and non-PCNA cultivars did not yield PCNA offspring (Ikeda et al. 1985). These results indicate that PCNA cultivars of Japanese origin 
Table 1. Estimated relationship between genotypes and phenotypes for alleles controlling astringency type (Yamada 2013)

\begin{tabular}{|c|c|c|c|c|}
\hline \multicolumn{3}{|c|}{ Genotype } & \multirow{2}{*}{ Phenotype } & \multirow{2}{*}{$\begin{array}{l}\text { Soluble tannin } \\
\text { accumulation }\end{array}$} \\
\hline Japanese PCNA locus & Chinese PCNA locus & PV locus (loci) & & \\
\hline \multirow{3}{*}{ A------ } & \multirow{4}{*}{ bbbbbb } & $\begin{array}{l}\text { CCCCCC, CCCCCc, } \\
\text { CCCCcc, CCCccc }\end{array}$ & PVNA & \multirow{3}{*}{$\bigcirc$} \\
\hline & & CCccec, $\mathrm{Cccccc}$ & PVA & \\
\hline & & $\operatorname{cccccc}$ & PCA & \\
\hline aаaаaа & & C------ or ceccec & Japanese PCNA & \multirow{2}{*}{$\times$} \\
\hline A------, or aаaаaа & B------- & C------ or ceccec & Chinese PCNA & \\
\hline
\end{tabular}

Estimated function of each allele.

A: accumulate soluble tannins into fruit; a: no function of the tannin accumulation.

B: suppress the tannin accumulation into fruit; $b$ : no function of the suppression of the tannin accumulation.

$\mathrm{C}$ : exclude acetaldehyde from seeds, and change soluble tannins to insoluble; c: no function to exclude acetaldehyde from seeds.

are not closely related to PCNA cultivars of Chinese origin and that the Chinese PCNA trait of 'Luotian-Tianshi' is genetically different from the Japanese PCNA trait. Therefore, we have denoted PCNA cultivars of Japanese and Chinese origin as J-PCNA and C-PCNA, respectively.

Yamada (2013) summarized and showed the relationships between the genotypes and phenotypes for the three astringency types, J-PCNA, C-PCNA, and PV (Table 1). Three loci control the astringency type: (1) the locus controlling the J-PCNA trait, denoted by A-a (the upper-case letter denotes a dominant allele and the lower-case letter denotes a recessive allele); (2) the locus controlling the C-PCNA trait, denoted by B-b; and (3) the locus controlling the PV trait, denoted by C-c. The PV trait has not been demonstrated to be controlled by a single locus, so its designation as a single locus here is hypothetical. The B alleles were hypothesized to suppress soluble tannin accumulation in fruits in the presence of A alleles, which normally function to accumulate soluble tannin substances in the tannin cells (Yamada 2013). Under this hypothesis, if a genotype having no A allele and one or more B alleles were obtained by breeding, it is estimated that the fruit would have very low concentrations of tannin substances, and would possibly have wide adaptability in cooler regions where temperatures are not high enough to fully remove astringency by harvest time (Yamada 2013).

Oriental persimmon germplasm in Japan and characteristics of local PCNA cultivars

The first recorded PVNA cultivar was 'Zenjimaru', which was mentioned in a 13th-century document, whereas the word "kaki" was mentioned as over-ripened or dried fruits in a 10th-century document (Kikuchi 1948), suggesting that the fruits in the 10th century were astringent type. Therefore, PVNA does not have a long history compared with that of the astringent cultivars. However, the PVNA local cultivars in Japan show wide variation, comparable to that of the PCA cultivars, and are distributed throughout the country, suggesting rapid development and dissemination of PVNA cultivars (Yamada et al. 1994a). PVNA offspring are com- monly found among the open-pollinated seeds of PVNA genotypes (Ikeda et al. 1985). These open-pollinated chance seedlings may have contributed to the rapid development of PVNA cultivars (Yamada et al. 1994a).

In contrast, local J-PCNA cultivars are distributed mostly within narrow geographic areas, including the Kinki and Tokai districts (Yamada 2005, Yamada et al. 1993a). Only one J-PCNA cultivar, 'Gosho', was widely grown 200 years ago (Kikuchi 1948). The existence of 'Gosho' was first mentioned in the 17th century (Kikuchi 1948), and it is assumed to be the oldest J-PCNA cultivar. It is probable that once 'Gosho' or its ancestral J-PCNA genotype appeared, natural repeated crossings between it and non-PCNA cultivars and their descendants resulted in the present J-PCNA local cultivars (Ikeda et al. 1985, Yamada 2005, Yamada et al. 1993a).

Consistent with their relatively recent appearance, JPCNA cultivars have little diversity in agricultural and morphological traits (Fig. 1; Yamada et al. 1993a, 1994a). Most J-PCNA cultivars ripen late (Yamada 1993, Yamada et al.

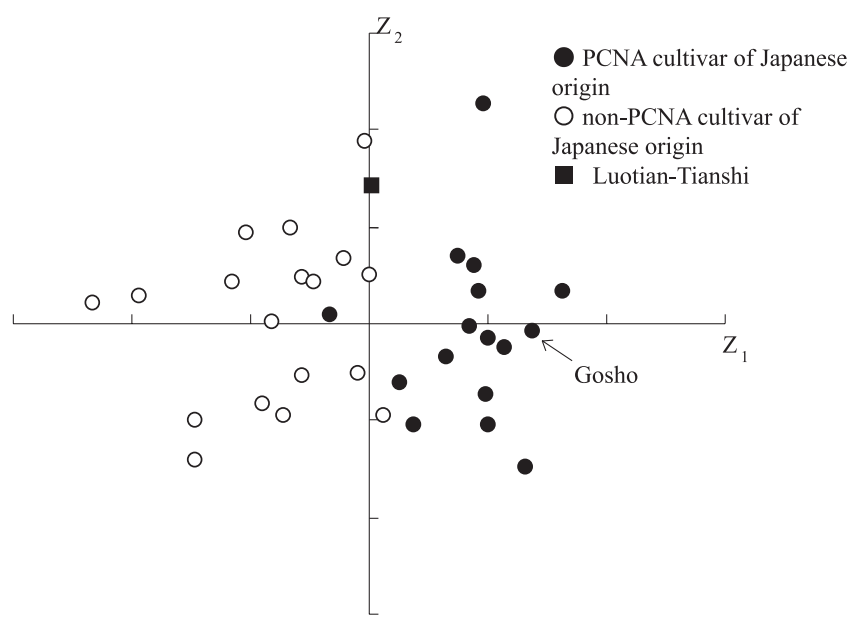

Fig. 1. Principal component scatter diagram on the first $\left(Z_{1}\right)$ and second $\left(Z_{2}\right)$ principal components for 18 fruit traits (Yamada et al. 1993a). J-PCNA cultivars were distinguished by their flat shape, fruit cracking at the calyx and stylar ends, many wrinkles on the fruit skin at the calyx end, and dark-colored and thick seeds shown by $Z_{1}$ axis. 
1994a) and the fruits tend to crack at the calyx end and/or stylar end (Yamada et al. 1988). Almost all have flatter fruit with many wrinkles on the fruit skin near the calyx end (Yamada et al. 1993a). The narrow area of distribution and the morphological similarities of J-PCNA cultivars suggest that these cultivars are closely related to one another. AFLP analysis (Kanzaki et al. 2000a, Yonemori et al. 2008) and SSR analysis (Naval et al. 2010) also suggest close genetic relationships among the J-PCNA cultivars.

Oriental persimmons exhibit three types of sex expression: only pistillate flowers (pistillate type), both pistillate and staminate flowers (monoecious type), and hermaphroditic flowers in addition to pistillate and staminate flowers (polygamomonoecious type) (Yonemori et al. 2000). The type of sex expression in a cultivar is determined genetically, although the pistillate-type cultivars (e.g., 'Fuyu' and 'Jiro') produce staminate flowers on very rare occasions (Yakushiji et al. 1995). Productivity partly depends on the quantity of pistillate flowers on the tree; therefore, most of the leading cultivars are of the pistillate type. Crossing between pistillate-type cultivars/selections is not normally possible, potentially leading to restrictions on choosing cross-combinations among cultivars/selections. However, the frequency of offspring of monoecious or polygamomonoecious type from crosses between pistillate-type cultivars and the other types was not low (Oohata et al. 1964). Moreover, there are many local cultivars of the monoecious or polygamomonoecious type, including half of the 18 local J-PCNA cultivars. Thus, sex expression has not been a serious hindrance to breeding for PCNA.

Persimmon breeding at the national institute in Japan

The persimmon breeding program at the national institute began in Okitsu in 1938 and moved to Akitsu in 1968, where it continues today. The program has focused on the release of superior PCNA cultivars. At the start of the program, there were only two leading J-PCNA cultivars ('Fuyu' and 'Jiro'), and both ripen late. Therefore, one of the most important breeding objectives was to develop superior early ripening PCNA cultivars (Yamada 1993, 2005). In addition, the following characteristics have been important in the breeding program: no-cracking habit, large fruit size, high eating quality (soft, juicy, and non-mealy flesh), high productivity, long shelf life, and good fruit appearance. Since the 1950 s, crosses have been mainly made among J-PCNA cultivars/selections.

Inheritance of fruit ripening time (FRT) is under additive and quantitative control (Yamada et al. 1995). FRT had high broad-sense heritability in a population of cultivars/selections used as cross-parents in the 1970s and 1980s at the national institute (Yamada et al. 1993b). Yamada et al. (1995) showed that no early ripening offspring were estimated to be obtained from crossing late ripening PCNA local cultivars. FRT in parental populations has gradually shifted toward early ripening through several cycles of selection over 50 years (Fig. 2).

The tendencies of persimmon fruit to crack at the calyx and/or stylar ends are quantitatively inherited traits; the non-cracking cultivars are homozygous, whereas cultivars with cracking are heterozygous (Yamada et al. 1988). Many local J-PCNA cultivars have cracking habits that are distinct from those of non-PCNA cultivars (Yamada et al. 1988). Consequently, crosses among crack-resistant parents are desirable, but difficult to carry out with most J-PCNA parents, which are crack-susceptible. Many selections had cracking at the calyx or stylar end or both, especially in the early generations of breeding (Yamada et al. 1988). However, careful selection over the past two decades has increased the frequency of offspring with no cracking (Yamada and Sato 2003). The levels of both cracking are environmentally influenced and fluctuate greatly from year to year (Yamada et al. 1986, 1987). Yamada et al. (2002a) showed that the largest component of the fluctuation is the genotype $\times$ year interaction.

Large fruit size (fruit weight, FW) is important for the
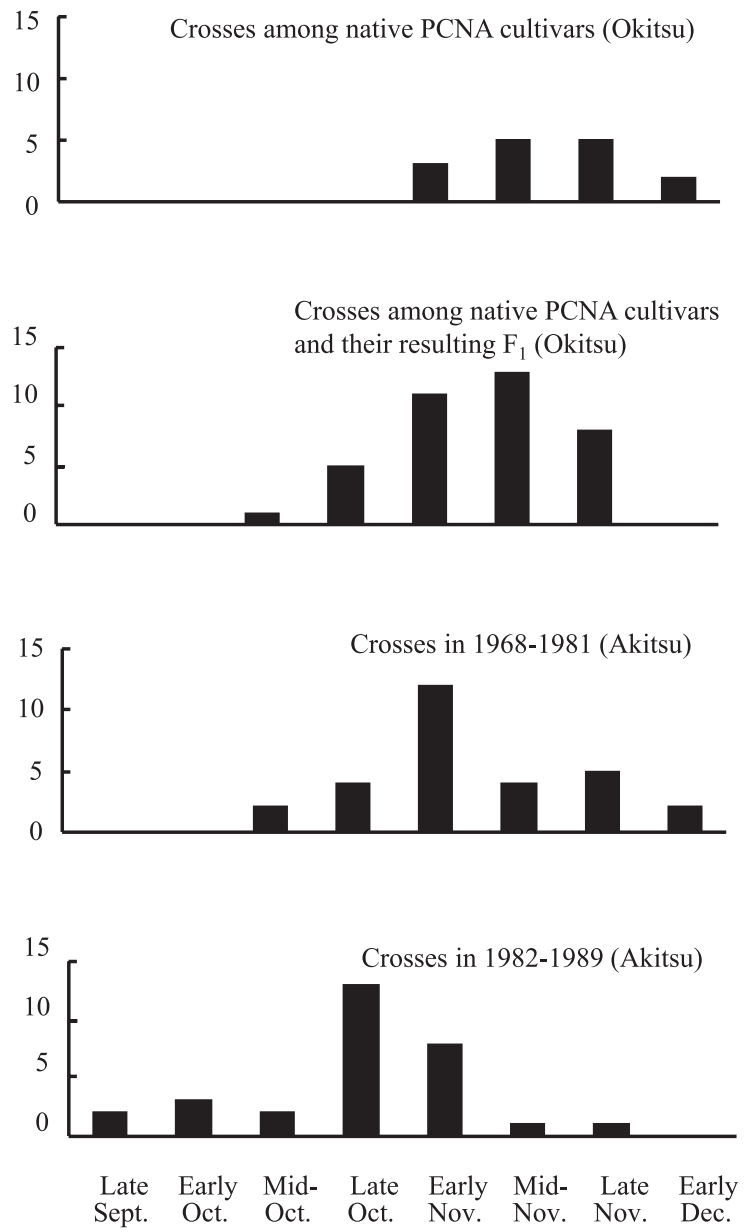

Fruit ripening time

Fig. 2. Fruit ripening time of PCNA or PCNA-derived cultivars and selections used as parents in Okitsu and Akitsu (Yamada 1993). 


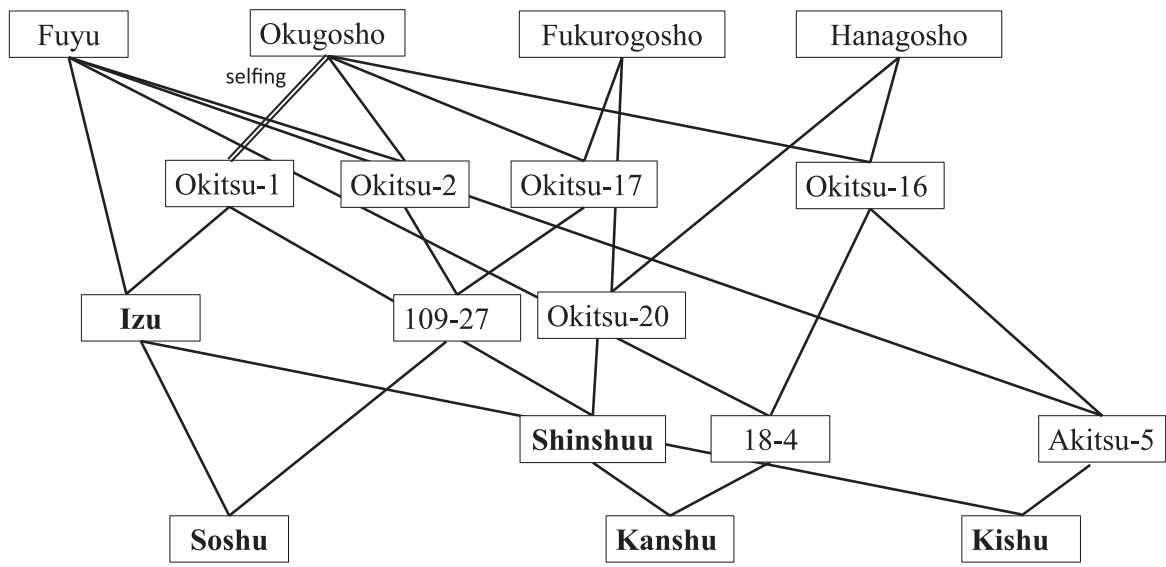

Fig. 3. Pedigrees of persimmon cultivars with early ripening fruit released by NIFTS.

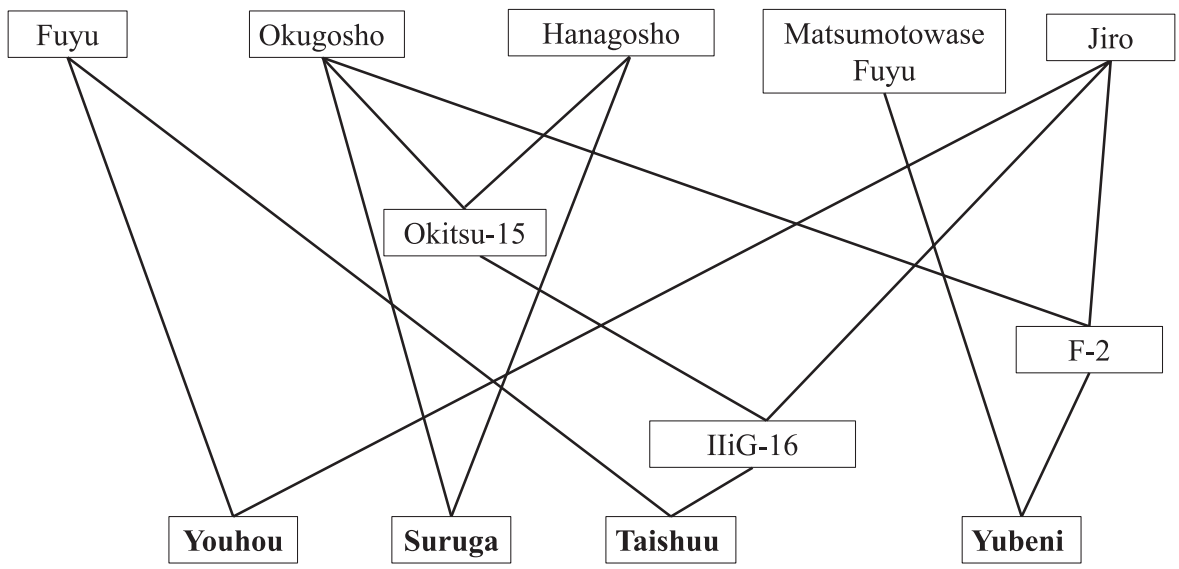

Fig. 4. Pedigrees of persimmon cultivars with mid to late ripening fruit released by NIFTS.

Japanese market. FW is a quantitative characteristic with high broad-sense heritability (Yamada et al. 1993b). Yamada et al. (1994b) showed that most of the genetic differences among families in progeny could be explained by the multiple regression of the mean value of a family on the inbreeding coefficient (F) and mid-parental value (MP), indicating that breeders can accurately predict the distribution of the genotypic values of offspring based on F and MP (Yamada et al. 1994b, Yamada and Yamane 1997). It should be emphasized that FW is influenced more by F than by MP, and FW is greatly reduced by inbreeding (i.e., higher $\mathrm{F}$ values). Thus, the narrow genetic diversity of local J-PCNA cultivars has hindered breeding aimed at producing offspring with large FW even though the local J-PCNA cultivar group has a larger mean FW than the local PCA and PVNA cultivar groups (Yamada et al. 1994a).

After prolonged efforts toward developing superior PCNA cultivars, the following early ripening J-PCNA cultivars have been released: 'Izu' (Hirose et al. 1971), 'Shinshuu' (Yamane et al. 1991a), 'Soshu' (Yamada et al. 2004), 'Kanshu' (Yamada et al. 2006), and 'Kishu' (Yamada et al. 2009). In addition, 'Suruga' (Iikubo et al. 1961), 'Youhou' (Yamane et al. 1991b), 'Taishuu' (Yamane et al.
2001), and 'Yubeni' (Yamada et al. 2003) have been released as medium to late ripening J-PCNA cultivars. The early ripening cultivars were developed by repeated crossing

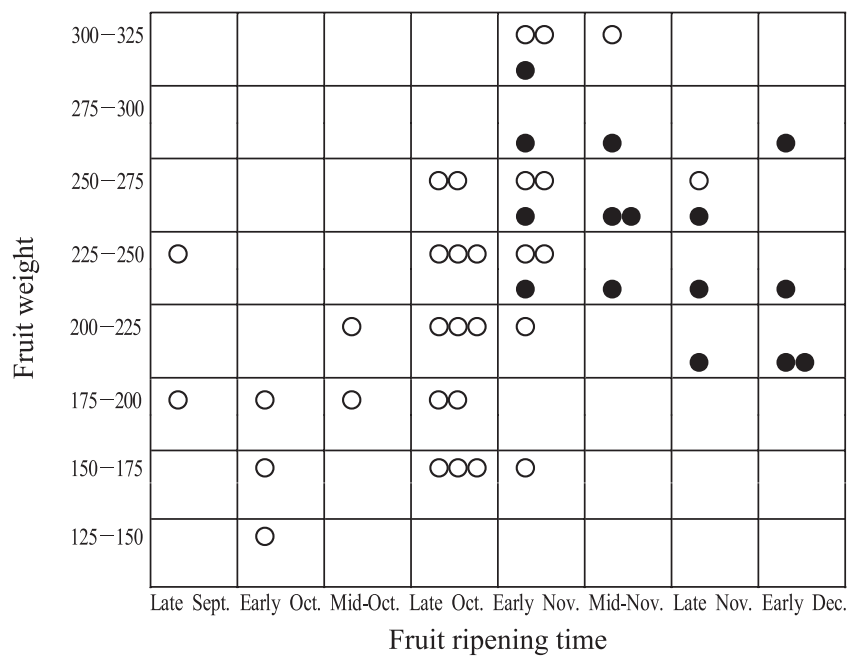

Fig. 5. Relationship between fruit ripening time and fruit weight in cross-parents in Okitsu and Akitsu (Yamada 1993). •: PCNA native cultivars used as parents in Okitsu. ○: PCNA used as parents in Akitsu. 
over generations within the narrow J-PCNA genetic resources; therefore, they are highly inbred (Fig. 3). On the other hand, the medium to late ripening cultivars resulted from crosses with low F values (Fig. 4). While FRT was controlled additively, inbreeding reduced FW in advanced early ripening generations (Fig. 5). Inbreeding depression influences not only FW but also tree vigor and productivity (Yamada 1993). The productivity of these new J-PCNA cultivars does not exceed that of 'Fuyu', a leading J-PCNA late ripening cultivar.

Development of molecular markers for discriminating J-PCNA and non-PCNAs

As described above, inbreeding depression was a serious problem in the 1980s breeding program aimed at developing early ripening J-PCNA cultivars (Yamada 1993). An approach to avoid inbreeding depression was started in 1990 and involved obtaining J-PCNA offspring from backcrosses $[(\mathrm{J}-\mathrm{PCNA} \times$ non-PCNA $) \times \mathrm{J}-\mathrm{PCNA}]$. This was an inefficient process because only around $15 \%$ of the offspring were PCNA (Ikeda et al. 1985), and all offspring had to be raised and kept in an orchard until fruiting. Therefore, there was a need to develop molecular markers for discriminating J-PCNA and non-PCNA genotypes in young seedlings so that non-PCNA offspring could be discarded soon after germination, before planting in an orchard.

The development of molecular markers linked to the $A S T$ locus began in 1997 as a cooperative study between the national institute and Kyoto University; the study was joined later by Kinki University. Kanzaki et al. (2001) tested 128 AFLP primer combinations using bulked segregant analysis of a population of 'Nishimurawase' (PVNA)-derived offspring. One particular primer set was found to be possibly linked to a dominant allele controlling the astringency trait: the marker was absent in all PCNA offspring but present in half of the non-PCNA individuals tested. Using this AFLP marker as a probe, restriction fragment length polymorphism (RFLP) analysis was performed, which enabled the detection of RFLP markers linked with two dominant alleles corresponding to the AFLP marker. One or both of these RFLP markers were present in non-PCNA offspring and absent in PCNA offspring. The alleles linked with these two RFLP markers were later named A1 and A2 (Kanzaki et al. 2009). Twelve Japanese PCNA cultivars from 20 nonPCNA cultivars were distinguished for astringency (PCNA or non-PCNA) with these RFLP markers (Kanzaki et al. 2000b).

Furthermore, Kanzaki et al. (2009) converted the RFLP markers into PCR-based sequence-characterized amplified region (SCAR) markers, PCR-A1 and PCR-A2, by using the primer pairs E4/A2r and E4/E9r, respectively. Kanzaki et al. (2009) also showed that these primer pairs were effective at discriminating J-PCNA offspring in a 'Nishimurawase'derived offspring population. However, the markers could not always discriminate J-PCNA offspring in a population derived from 'Kurokuma' (non-PCNA), suggesting the existence of another polymorphism in the $A S T$-allele-linked region in 'Kurokuma'. Therefore, Kanzaki et al. (2010) directly sequenced the genomic region adjacent to the ASTlinked region, and developed a multiplex PCR procedure using two forward primers, AST-F and PCNA-F, and a reverse primer, 5R3R. Using these primers, an additional polymorphism at the $A S T$ locus (designated the A3 allele) could be detected in 'Kurokuma' by using a single PCR (Fig. 6). These SCAR markers have been applied to offspring from two backcross families using 'Taigetsu' (JPCNA × 'Kurokuma'; Yamada et al. 2012b) and 'Taiten' (J-PCNA × 'Kurokuma'; Yamada et al. 2012c). The effectiveness of these markers has been confirmed in practical persimmon breeding (Mitani et al. 2014a, 2014b).

Recently, Akagi et al. $(2009,2010)$ genotyped the AST locus by measuring the $A S T$ to ast ratio using quantitative real-time PCR. They estimated that only $5 \%$ of non-PCNA cultivars of Japanese origin have four or more ast alleles, whereas $75 \%$ have two or fewer. Yamada (2013) pointed out that this finding was in agreement with the almost complete absence of PCNA offspring from local Japanese non-PCNA and J-PCNA crosses reported by Ikeda et al. (1985).

Non-PCNA cultivars, 'Yoshino', 'Egosho', and 'Busshigano', all of which have a high ast allele dosage, originated near the area of origin of 'Gosho' or other major PCNA cultivars, suggesting that the accumulation of ast alleles and the resultant generation of the PCNA phenotype occurred around the region where 'Gosho' arose (Akagi et al. 2010). In addition, the ast allele was widely found not only in Japanese local non-PCNA cultivars but also in astringent cultivars of Chinese and Korean origin (Akagi et al. 2010).

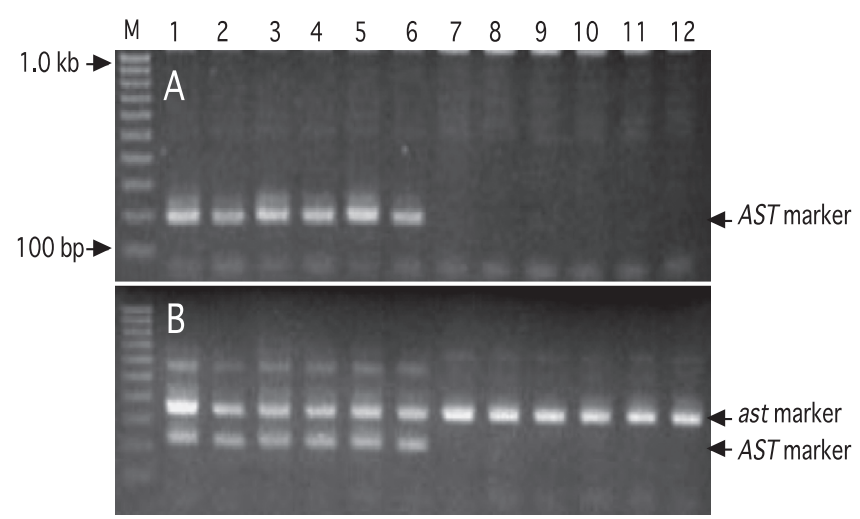

Fig. 6. Segregation of the SCAR markers in offspring in a backcross [('Kurokuma' × 'Taishuu') × 109-27] family (Kanzaki et al. 2010). Lane 1-6: non-PCNA-type offspring, Lane 7-12: PCNA-type offspring. M: 100-bp ladder size marker. A: polymorphisms detected by the SCAR primer pair AST-F/AST-R. The 190-bp fragment was presented in all non-PCNA-type offspring, but not in PCNA-type offspring. B: Amplified fragments of multiplex PCR by the primer pair AST-F/PCNA-F/5R3R. All offspring showed the ast-linked 350-bp fragment while only non-PCNA-type offspring showed the AST-linked 220-bp fragment. 
Akagi et al. (2009) showed that an autohexaploid model for inheritance of DNA markers at the AST locus generally fitted the expected ratio, with a few exceptions. These findings confirm that the low probability of obtaining J-PCNA offspring from crossing between J-PCNA cultivars/selections and local non-PCNA cultivars is due to the hexaploid nature of persimmon. Assuming that the theoretical genetic behavior of autopolyploids (Allard 1960), i.e., random chromosome or chromatid assortment, applies to persimmon, in the cross non-PCNA $\times$ J-PCNA, non-PCNA parents with less than two ast alleles would not yield any J-PCNA offspring, those with two ast alleles would yield $0-0.2 \%$ J-PCNA offspring, those with three ast alleles would yield 5-9\% J-PCNA offspring, those with four ast alleles would yield 20-25\% J-PCNA offspring, and those with five ast alleles would yield 50-55\% J-PCNA offspring (Yamada 2013).

The genotyping of the AST locus provides useful information for practical breeding, particularly for choosing parents. For instance, crossing an Aaaaaa genotype with JPCNA is expected to produce $50-55 \% \mathrm{~J}-\mathrm{PCNA}$ offspring. Moreover, crosses among local non-PCNA cultivars with high dose ast allele would be expected to yield J-PCNA progeny. In the breeding program at the national institute, DNA marker selection is being used to screen backcross populations and local non-PCNA cultivars to identify non-PCNA individuals that have Aaaaaa or AAaaaa genotypes as candidates for parents in future breeding crosses.

Development of molecular markers for discriminating C-PCNA

A cross between 'Luotian-Tianshi' and the J-PCNA cultivar 'Taishuu' was made in 1992 at the national institute, and the progeny segregated for PCNA and non-PCNA offspring (Ikegami et al. 2004). Subsequently, 'Luotian-Tianshi' was crossed to non-PCNA cultivars, and segregation among the offspring showed that the C-PCNA character of 'Luotian-Tianshi' was dominant and controlled by a single locus (the B/b locus) (Ikegami et al. 2006). Therefore, 'Luotian-Tianshi' has potential as an important cross-parent for PCNA breeding because it is expected to produce 50\% PCNA offspring in the $F_{1}$ generation in crosses with either J-PCNA or non-PCNA. It would be advantageous as a cross-parent for avoiding inbreeding depression owing to its distant relationship with cultivars of Japanese origin (Kanzaki et al. 2000a). Three putative AFLP candidate bands were identified from screening 384 primer combina- tions in a bulked segregant analysis of offspring from a cross between 'Luotian-Tianshi' and J-PCNA cultivar 'Okugosho'. One of these AFLP markers was successfully converted to a PCR-based SCAR marker that was tightly linked to the C-PCNA dominant (B) allele (Ikegami et al. 2011). This PCR-based marker has been used for persimmon breeding (C-PCNA $\times$ Japanese cultivars) at the national institute.

Current status and future prospects of markerassisted selection for astringency type

In the breeding program at the national institute, $1346 \mathrm{~J}-$ PCNA and 439 C-PCNA offspring have been identified to be PCNA by DNA markers. These offspring have been selected from backcrosses [(non-PCNA $\times$ J-PCNA $) \times \mathrm{J}$-PCNA] and crosses between C-PCNA and non-C-PCNA cultivars/ selections of Japanese origin, respectively (Table 2). At present, three PCNA selections from the backcross program are being tested for the national regional trial.

The natural astringency loss on the tree in J-PCNA requires high temperatures in summer and autumn (Chujo et al. 1972, Yamada 2006). Complete astringency loss on the tree in 'Gosho', 'Hanagosho', and 'Yamatogosho' requires higher summer and autumn temperatures than are required for 'Fuyu', a widely grown cultivar. There is a small varietal difference in the degree of natural astringency loss on the tree among J-PCNA cultivars at the national institute in Akitsu, Hiroshima, Japan. In addition, fruit of the C-PCNA cultivars 'Luotian-Tianshi' and 'Tianbaogai' have a slight astringency at harvest at that location. To overcome these environmental effects, development of PCNA cultivars with complete astringency loss on the tree across a wide range of areas is an important breeding target. One strategy is to develop cultivars nulliplex for the A-a locus (aaaaa) and carrying one or more B alleles (Yamada 2013). So far, no cultivars of this genotype have yet been developed, and the strategy is thus unproven but is undergoing testing at the national institute.

Epistasis between loci controlling the astringency type (PCNA trait) and tree vigor and productivity has not been reported. Primarily, to develop highly productive cultivars, it is important for the breeding program to develop evaluation methods with high broad-sense heritability for tree vigor and productivity. Recently, Sato et al. (2013) showed that FW in J-PCNA offspring is slightly but significantly lower than that in non-PCNA offspring in two backcross families. Katayama-Ikegami et al. (2013) showed that the fruit of

Table 2. Current status of marker-assisted selection for astringency type in the national institute persimmon breeding program (2003-2014)

\begin{tabular}{lclrr}
\hline \hline Aim of cross & No. of cross & \multicolumn{1}{c}{ Cross type } & $\begin{array}{c}\text { No. of individuals tested for } \\
\text { marker-assisted selection }\end{array}$ & $\begin{array}{c}\text { No. of individuals } \\
\text { selected }\end{array}$ \\
\hline J-PCNA $^{a}$ & 28 & Backcross [(non-PCNA $\times$ J-PCNA) $\times$ J-PCNA)] & 5724 & 1346 \\
C-PCNA $^{b}$ & 10 & C-PCNA $\times$ non C-PCNA & 849 & 439 \\
\hline
\end{tabular}

${ }^{a}$ Pollination constant and non-astringent with Japanese origin.

${ }^{b}$ Pollination constant and non-astringent with Chinese origin. 
C-PCNA offspring are flatter than those of non-PCNA offspring, although FW is not significantly different between them. Studies on PCNA gene expression are needed for further persimmon breeding.

\section{Acknowledgements}

We would like to thank Drs. Atsushi Kono and Noriyuki Onoue for their critical reading of the manuscript.

\section{Literature Cited}

Agricultural Research Station (1912) Investigation on persimmon cultivars. Bull. Agr. Res. Sta. (extra) 28: 1-46.

Akagi,T., S.Kanzaki, M.Gao, R.Tao, D.E. Parfitt and K. Yonemori (2009) Quantitative real-time PCR to determine allele number for the astringency locus by analysis of a linked marker in Diospyros kaki Thunb. Tree Genet. Genomes 5: 483-492.

Akagi, T., Y.Takeda, K. Yonemori, A.Ikegami, A. Kono, M. Yamada and S. Kanzaki (2010) Quantitative genotyping for the astringency locus in hexaploid persimmon cultivars using quantitative realtime PCR. J. Amer. Soc. Hort. Sci. 135: 59-66.

Allard, R.W. (1960) Principles of Plant Breeding. John Wiley \& Sons, Inc., New York and London, $485 \mathrm{p}$.

Cho, S.K. and T.H. Cho (1965) Studies on the local varieties of persimmon in Korea. Res. Rep. RDA 8: 147-190.

Chujo, T., M. Kataoka, S. Yamauchi and M.Ashizawa (1972) Effect of temperature on the growth and quality of Kaki fruit. I. on the temperature treatment during the stage of fruit enlargement. J. Japan. Soc. Hort. Sci. 41: 339-343.

Food and Agriculture Organization of the United Nations (2015) FAOSTAT (http: //faostat.fao.org/).

Hirose, K., M. Yamamoto, T.Sato, T. Ohata, T.Nishida, I.Ikeda, I. Shimura, S. Siba, M. Yagi and N. Tominaga (1971) New Japanese persimmon variety 'Izu'. Bull. Hort. Res. Sta. B 11: 1-17.

Hume, H.H. (1914) A kaki classification. J. Hered. 5: 400-406.

Iikubo, S., T.Sato and T.Nishida (1961) New Japanese persimmon variety 'Suruga'. Bull. Hort. Sta. Natl. Tokai-Kinki Agr. Exp. Sta. 6: $33-37$.

Ikeda, I., M. Yamada and A. Kurihara (1985) Inheritance of astringency in Japanese persimmon (Diospyros kaki Thunb.). J. Japan. Soc. Hort. Sci. 54: 39-45.

Ikegami,A., K. Yonemori, A. Sugiura, A. Sato and M. Yamada (2004) Segregation of astringency in $\mathrm{F}_{1}$ progenies derived from crosses between pollination-constant, non-astringent persimmon cultivars. HortScience 39: 371-374.

Ikegami,A., A. Sato, M. Yamada, A. Kitajima and K. Yonemori (2005) Molecular size profiles of tannins in persimmon fruits of Japanese and Chinese pollination-constant non-astringent (PCNA)-type cultivars and their offspring revealed by size-exclusion chromatography. J. Japan. Soc. Hort. Sci. 74: 437-443.

Ikegami,A., S. Eguchi, K. Yonemori, M. Yamada, A. Sato, N. Mitani and A. Kitajima (2006) Segregations of astringent progenies in the $\mathrm{F}_{1}$ populations derived from crosses between a Chinese pollinationconstant nonastringent (PCNA) 'Luo Tian Tian Shi', and Japanese PCNA and pollination-constant astringent (PCA) cultivars of Japanese origin. HortScience 41: 561-563.

Ikegami,A., S.Eguchi, T.Akagi, A.Sato, M. Yamada, S. Kanzaki, A. Kitajima and K. Yonemori (2011) Development of molecular markers linked to the allele associated with the non-astringent trait of the Chinese persimmon (Diospyros kaki thumb.). J. Japan. Soc.
Hort. Sci. 80: 150-155.

Kajiura, M. (1946) Persimmon cultivars and their improvement 2. Breed. Hort. 1: 175-182.

Kanzaki, S., K. Yonemori, A. Sato, M. Yamada and A. Sugiura (2000a) Analysis of the genetic relationships among pollination-constant and non-astringent (PCNA) cultivars of persimmon (Diospyros kaki Thunb.) from Japan and China using amplified fragment length polymorphism (AFLP). J. Japan. Soc. Hort. Sci. 69: 665670.

Kanzaki, S., K. Yonemori, A. Sato, M. Yamada and A. Sugiura (2000b) Evaluation of RFLP analysis for discriminating PCNA genotype in some persimmon cultivars. J. Japan. Soc. Hort. Sci. 69: 702-704.

Kanzaki, S., K. Yonemori, A. Sugiura, A. Sato and M. Yamada (2001) Identification of molecular markers linked to the trait of natural astringency loss of Japanese persimmon (Diospyros kaki) fruit. J. Amer. Soc. Hort. Sci. 126: 51-55.

Kanzaki, S., M. Yamada, A. Sato, N. Mitani, N. Utsunomiya and K. Yonemori (2009) Conversion of RFLP markers for the selection of pollination-constant and non-astringent type persimmons (Diospyros kaki Thunb.) into PCR-based markers. J. Japan. Soc. Hort. Sci. 78: 68-73.

Kanzaki, S., T.Akagi, T.Masuko, M.Kimura, M.Yamada, A. Sato, N. Mitani, N. Utsunomiya and K. Yonemori (2010) SCAR markers for practical application of marker-assisted selection in persimmon (Diospyros kaki Thunb.) breeding. J. Japan. Soc. Hort. Sci. 79: $150-155$.

Katayama-Ikegami, A., K. Yonemori, A. Sato, M. Yamada, T. Habu and A. Kitajima (2013) Relationship between astringency type and fruit shape in progenies of Chinese PCNA persimmon. Hort. Res. (Japan) 12: 29-34.

Kikuchi,A. (1948) Pomology-part I. Yokendo, Tokyo, pp. 347-400.

Kitagawa,H. (1970) Persimmon culture and use, Yokendo, Tokyo, pp. 181-232.

Kitagawa,H. and P.G.Glucina (1984) Persimmon culture in New Zealand, Science Information Publishing Centre, DSIR. Wellington, New Zealand, pp. 3-14.

Luo, Z., F. Li and L. Cai (1999) Molecular systematics of China native non-astringent persimmon based on random amplified polymorphic DNA. Acta Horticulturae Sinica 26: 297-301.

Ministry of Agriculture, Forestry and Fisheries (2015) Sakkyo chosa (Kaju) (Survey of harvest situation of fruit) (http: //www.maff.go. jp/j/tokei/kouhyou/sakumotu/sakkyou_kazyu/index.html).

Mitani, N., A.Kono, M. Yamada, A. Sato, S.Kobayashi, Y.Ban, T. Ueno, M. Shiraishi, S. Kanzaki, T. Tsujimoto et al. (2014a) Application of marker-assisted selection in persimmon breeding of PCNA offspring using Scar markers among the population from the cross between non-PCNA 'Taigetsu' and PCNA 'Kanshu'. HortScience 49: 1132-1135.

Mitani, N., A.Kono, M. Yamada, A.Sato, S.Kobayashi, Y.Ban, T. Ueno, M. Shiraishi, S. Kanzaki, T. Tsujimoto et al. (2014b) Practical marker-assisted selection using two SCAR markers for fruit astringency type in crosses of 'Taiten' $\times$ PCNA cultivars in persimmon breeding. Sci. Hortic. 170: 219-223.

Naval,M., E.Zuriaga, S.Pecchioli, G.Llacer, E.Giordani and M.L. Badness (2010) Analysis of genetic diversity among persimmon cultivars using microsatellite markers. Tree Genet. Genomes 6: $677-687$.

Oohata, T., I. Ikeda and T. Nihida (1964) The inheritance of some characters in Japanese persimmon (Diospyros kaki). II. The inheritance of bearing habit of staminate flowers. Bull. Hort. Res. Stn. B3: 5166.

Sato, A., A. Kono, N. Mitani, Y. Ban and M. Yamada (2013) Comparison 
of fruit traits between pollination constant and non-Astringent (PCNA) and non-PCNA offspring derived from two backcrosses $($ non-PCNA $\times$ PCNA) $\times$ PCNA. Acta Hortic. 996: 123-126.

Sugiura,A. and T. Tomana (1983) Relationships of ethanol production by seeds of different types of Japanese persimmons and their tannin content. HortScience 18: 319-321.

Wang, R. (1982) The origin of 'Luotian-Tianshi'. Chinese Fruit Tree 2: $16-19$.

Wang, R., Y.Yang and G.Li (1997) Chinese persimmon germplasm resources. Acta Hortic. 436: 43-50.

Yakushiji, H., M. Yamada, K. Yonemori, A. Sato and N. Kimura (1995) Staminate flower production on shoots of 'Fuyu' and 'Jiro' persimmon (Diospyros kaki Thunb.). J. Japan. Soc. Hort. Sci. 64: 41-46.

Yamada, M., H. Yamane and T.Hirabayashi (1986) Studies on crossbreeding of Japanese persimmon (Diospyros kaki Thunb.), V. Variation of "Hetasuki" (fruit cracking under the calyx). Bull. Fruit Tree Res. Stn. E6: 21-30.

Yamada, M., H. Yamane and T. Hirabayashi (1987) Yearly fluctuations of two types of fruit cracking in seedling populations of Japanese persimmon (Diospyros kaki Thunb). J. Japan. Soc. Hort. Sci. 56: 287-292.

Yamada, M., I. Ikeda, H. Yamane and T. Hirabayashi (1988) Inheritance of fruit cracking at the calyx end and stylar end in Japanese persimmon (Diospyros kaki Thunb.). J. Japan. Soc. Hort. Sci. 57: 8-16.

Yamada, M. (1993) Persimmon breeding in Japan. Jpn. Agr. Res. Quart. 27: 33-37.

Yamada, M., A.Sato, H.Yakushiji, K.Yoshinaga, H. Yamane and M.Endo (1993a) Characteristics of 'Luo Tian Tian Shi', a nonastringent cultivar of oriental persimmon (Diospyros kaki Thunb.) of Chinese origin in relation to non-astringent cultivars of Japanese origin. Bull. Fruit Tree Res. Stn. 25: 19-32.

Yamada, M., H. Yamane, K. Yoshinaga and Y.Ukai (1993b) Optimal spatial and temporal measurement repetition for selection in Japanese persimmon breeding. HortScience 28: 838-841.

Yamada, M., H.Yamane, A. Sato, N. Hirakawa and R. Wang (1994a) Variations in fruit ripening time, fruit weight and soluble solids content of oriental persimmon cultivars native to Japan. J. Japan. Soc. Hort. Sci. 63: 485-492.

Yamada, M., H. Yamane and Y. Ukai (1994b) Genetic analysis of Japanese persimmon fruit weight. J. Amer. Soc. Hort. Sci. 119: 12981302.

Yamada, M., H. Yamane and Y.Ukai (1995) Genetic analysis of fruit ripening time in Japanese persimmon. J. Amer. Soc. Hort. Sci. 120: 886-890

Yamada, M. and H. Yamane (1997) Relationship between the observed and predicted distribution of offspring for fruit ripening time and fruit weight in Japanese persimmon. Sci. Hortic. 69: 157-167.

Yamada, M. and A. Sato (2002) Segregation for fruit astringency type in progenies derived from crosses of 'Nishimurawase' $\times$ pollination constant non-astringent genotypes in Oriental persimmon (Diospyros kaki Thunb.). Sci. Hortic. 92: 107-111.

Yamada, M., A. Sato and Y. Ukai (2002a) Genetic differences and environmental variations in calyx-end fruit cracking among Japanese persimmon cultivars and selections. HortScience 37: 164-167.

Yamada, M., S. Taira, M. Ohtsuki, A.Sato, H. Iwanami, H. Yakushiji, R. Wang, Y. Yang and G.Li (2002b) Varietal differences in the ease of astringency removal by carbon dioxide gas and ethanol vapor treatments among oriental astringent persimmons of Japanese and Chinese origin. Sci. Hortic. 94: 63-72.

Yamada, M. and A. Sato (2003) Status of persimmon breeding at the National Institute of Fruit Tree Science, Japan. Options Mediterra- neennes Series A 51: 75-79.

Yamada, M., H. Yamane, A. Kurihara, K.Nagata, A. Sato, T.Kishi, R. Matsumoto, K. Yoshinaga, N. Hirakawa, H. Iwanami et al. (2003) New Japanese persimmon cultivar 'Yubeni'. Bull. Natl. Inst. Fruit Tree Sci. 2: 65-75.

Yamada, M., H.Yamane, A. Sato, H.Iwanami, N. Hirakawa, K. Yoshinaga, T. Ozawa and I.Nakajima (2004) New Japanese persimmon cultivar 'Soshu'. Bull. Natl. Inst. Fruit Tree Sci. 3: 53-66.

Yamada, M. (2005) Persimmon genetic resources and breeding in Japan. Acta Hortic. 685: 51-64.

Yamada, M. (2006) Persimmon. The Japanese Society for Horticultural Science (eds.) Horticulture in Japan, Nakanishi Printing Co, Ltd, Kyoto, pp. 72-81.

Yamada, M., H.Yamane, A.Sato, N. Hirakawa, H.Iwanami, K. Yoshinaga, T. Ozawa, M.Kakutani, N. Mitani, M. Yoshioka et al. (2006) New Japanese persimmon cultivar 'Kanshu'. Bull. Natl. Inst. Fruit Tree Sci. 5: 95-106.

Yamada, M., H.Yamane, A.Sato, K. Yoshinaga, N. Hirakawa, H. Iwanami, T. Ozawa, T. Hirabayashi, M. Kakutani, M. Shiraishi et al. (2009) A new Japanese persimmon cultivar, 'Kishu'. Bull. Natl. Inst. Fruit Tree Sci. 8: 25-38.

Yamada, M., E. Giordani and K. Yonemori (2012a) Persimmon. In: Badness, M.L. and D.H. Byrne (eds.) Fruit breeding, Handbook of plant breeding, Springer, New York, pp. 663-693.

Yamada, M., A. Sato, H. Yamane, N. Mitani, H. Iwanami, M. Shiraishi, N. Hirakawa, T.Ueno, A.Kono, M. Yoshioka et al. (2012b) New persimmon cultivar 'Taigetsu'. Bull. NARO Inst. Fruit Tree Sci. 14: $25-38$

Yamada, M., A. Sato, H. Yamane, N. Mitani, H. Iwanami, M. Shiraishi, N. Hirakawa, T.Ueno, A.Kono, M. Yoshioka et al. (2012c) New persimmon cultivar 'Taiten'. Bull. NARO Inst. Fruit Tree Sci. 14: $39-52$.

Yamada, M. (2013) Breeding goals, trait heredity and genetic improvement of persimmon in Japan. Acta Hortic. 996: 77-88.

Yamane, H., A. Kurihara, K. Nagata, M. Yamada, T. Kishi, K. Yoshinaga, R. Matsumoto, T. Ozawa, T.Sumi, T.Hirabayashi et al. (1991a) New Japanese persimmon cultivar 'Shinshuu'. Bull. Fruit Tree Res. Stn. 19: 13-27.

Yamane, H., A. Kurihara, K. Nagata, M. Yamada, T. Kishi, K. Yoshinaga, R. Matsumoto, K. Kanato, T.Sumi, T. Hirabayashi et al. (1991b) New Japanese persimmon cultivar 'Youhou'. Bull. Fruit Tree Res. Stn. 19: 49-61.

Yamane, H., M. Yamada, A. Kurihara, A. Sato, K. Yoshinaga, K. Nagata, R. Matsumoto, N. Hirakawa, M. Kakutani, T. Ozawa et al. (2001) New Japanese persimmon cultivar 'Taishuu'. Bull. Fruit Tree Res. Stn. 31: 15-24.

Yonemori, K. and J.Matsushima (1985) Property of development of the tannin cells in non-astringent type fruits of Japanese persimmon (Diospyros kaki) and its relationship to natural deastringency. J. Japan. Soc. Hort. Sci. 54: 201-208.

Yonemori, K., A. Sugiura and M. Yamada (2000) Persimmon genetics and breeding. Plant Breed. Rev. 19: 191-225.

Yonemori, K., A. Ikegami, A. Kitajima, Z.Luo, S. Kanzaki, A. Sato, M. Yamada, Y. Yang and R. Wang (2005) Existence of several pollination constant non-astringent type persimmons in China. Acta Hortic. 685: 77-83.

Yonemori, K., C.Honsho, A.Kitajima, M.Aradhya, E. Giordani, E. Bellin and D.E. Parfitt (2008) Relationship of European persimmon (Diospyros kaki Thunb.) cultivars to Asian cultivars, characterized using AFLPs. Genet. Resour. Crop Evol. 55: 81-89. 